OPEN ACCESS

Edited by:

Lin Zhang,

Ningbo University, China

Reviewed by:

Yongjun Zhang,

Stony Brook University, United States

Congcong Han,

Shandong Normal University, China

${ }^{*}$ Correspondence:

Xiaoyi Fang

fangxy@bnu.edu.cn

Specialty section:

This article was submitted to Evolutionary Psychology,

a section of the journal

Frontiers in Psychology

Received: 19 June 2020

Accepted: 20 August 2020 Published: 24 September 2020

Citation:

Hou J, Shu T and Fang X (2020) Influence of Resources on Cue Preferences in Mate Selection.

Front. Psychol. 11:574168. doi: 10.3389/fpsyg.2020.574168

\section{Influence of Resources on Cue Preferences in Mate Selection}

\author{
Juan Hou', Tianxin Shu' and Xiaoyi Fang ${ }^{2 *}$ \\ ${ }^{1}$ Department of Philosophy, Anhui University, Hefei, China, ${ }^{2}$ Institute of Developmental Psychology, Beijing Normal University, \\ Beijing, China
}

According to the research on the influence of resources on mate selection, the amount of financial resources affects an individual's choice of "luxuries" and "necessities" among mate selection cues, while the amount of time resources affects cue diversity. However, for a long time, researchers only paid attention to the impact of financial resources and ignored the role of time resources. Therefore, this paper draws lessons from the relevant research on the influence of time on decision-making and proposes to study mate selection from the perspective of decision-making. Additionally, current research concerning the influence of resources on the choice of a spouse focuses more on results and neglects to examine the process. Therefore, based on the relevant theories, this paper makes several theoretical assumptions regarding the influence mechanism of resource availability on mate choice decisions, gender differences, and the actor-partner effect.

Keywords: financial resources, time resources, mate choice decision, cue preference, influence mechanism

\section{INTRODUCTION}

Mate selection is an important link in the continuous development of human society and a complex decision-making problem (Svenson, 1996; Candolin, 2003; Li et al., 2016d). Mate selection involves not only the cue preference of individuals in the choice of partners but also the methods used by individuals in mate choice (Liu et al., 2011). This paper focuses on cue preference in the choice of partners.

Resources, as an important bargaining chip in mate selection, play a decisive role in the process of mate choice decision-making and have attracted the attention of many researchers (Buss, 1989; Yong and Li, 2012; Li et al., 2016a; Chen and Yao, 2018; Tian et al., 2019). Numerous other factors also affect individual preferences for mate cues, such as culture, the actual sex ratio, values, mate value, aesthetic standards, the mate selection purpose, and resource acquisition ability (Buss, 1989; Chang et al., 2011; Durante et al., 2012; Dillon et al., 2013). This paper mainly discusses the impact of resources.

Generally, the amount of resources influences the dimension and degree of the preference for mate selection cues in the mate selection decision. For example, men with more financial resources have higher requirements regarding women's physical attractiveness (Janssens et al., 2011; Yong and Li, 2012; Li et al., 2016a), while women consider men's resources regardless of their resources (Townsend, 1989; Khallad, 2005; Vigil et al., 2006). In addition, an increase in their own financial resources will lead women to pay more attention to the appearance and character of men (Gangestad and Simpson, 2000; Lu et al., 2015). 
Regarding the impact of resources on mate choice, money is an obvious factor, but resources include not only money but also time (Leclerc et al., 1995). The time resource discussed in this paper refers to the time available to individuals from the beginning of the mate choice decision to the completion of the mate choice decision. Studies have found that an abundance of time will affect the process and outcome of mate selection (Liu et al., 2011). When time resources are sufficient, individuals tend to consider more dimensions of mate preference, while the opposite is true when time resources are scarce. The amount of time resources also affects the information-processing mode of mate selection; that is, do people use rational analytical methods or heuristic methods of bounded rationality to make mate choices? (Liu et al., 2011; Li et al., 2016d). Unfortunately, the research on the influence of time resources on mate selection has not advanced since the cited publications, and additional research is required concerning the influence of time resources on mate selection and its mechanism.

Time and money display both similarities and differences. As a resource, time has much in common with financial resources, as both are limited resources that can be saved, spent or utilized (Li and Huang, 2013; Mogilner and Norton, 2016). However, time resources also possess several unique characteristics different from the characteristics of financial resources (Mogilner and Aaker, 2009; Li and Huang, 2013; Gino and Mogilner, 2014; Zhao, 2015; Hershfield et al., 2016). As one example, time resources cannot be replenished. Once lost, they cannot be recovered. Therefore, individuals may be more cautious with respect to spending time resources. Time resources also have no social exchange significance. In addition, because time resources have no material substance, they are conceptually vaguer and more difficult to measure than financial resources, and, therefore, individuals are less sensitive to sunk time costs than to sunk money costs (DeVoe and Pfeffer, 2007; Zhao, 2015). Moreover, time resources cannot be stored. Thus, although a day lasts the same $24 \mathrm{~h}$ for everyone, everyone's financial resources differ. Finally, the value of time resources is unstable and changes according to an individual's experience and age, while financial resources are subject to a unified value metric.

Based on the preceding discussion, this paper summarizes the relevant theories and studies on the influence of resources on cue preference in mate selection decisions while considering the two aspects of money and time. In addition, it presents a theoretical description of the influence mechanism of resources on mate selection decisions.

\section{THEORETICAL MODEL}

Researchers have proposed theoretical models of mate selection from several perspectives. In the early stage of this research, mate selection was typically studied from the perspective of evolutionary psychology as a means of reproduction. However, mate selection is both a biological instinct and a result of socialization. For example, positive assortative mating theory, complementarity theory, and social exchange theory elaborate the relationship between resources and mate selection from the perspective of sociology. In recent years, researchers have proposed considering mate selection as a type of decision made in pursuit of optimization. Therefore, a theoretical model that captures the influence of resources on decision-making would represent a valuable reference.

\section{Reproduction: Genetic Optimal Perspective}

Researchers have different views on how resources are integrated to achieve optimal reproduction. Evolutionary psychologists argue that the ultimate goal of human mate selection behavior is to reproduce and that all individual mate selection strategies aim to preserve and optimize the actor's own genes.

According to the theory of parental investment proposed by Trivers (1972), the purpose of mate selection is the continuation of the race, and both men and women have different incentives due to their different parental investments. That is, women value money more, while men value appearance more. Because women invest more in the reproduction and raising of their offspring and take more initiative, they pay more attention to the characteristics that are conducive to the raising of offspring, such as economic resources and social status. Of course, the requirements for these characteristics can also be used to screen for good male genes. To favor genetic continuation, the male, as a passive selector, tends to focus on the female's appearance and other characteristics with respect to gene optimization rather than valuing extensive economic resources.

Reproductive strategy theory, which also focuses on offspring investment, emphasizes the influence of early family life experience on mate selection. Belsky (1991) divided reproductive strategies into high reproductive strategies and low reproductive strategies according to the amount of investment in offspring. Individuals with high reproductive strategies tend to invest more emotion and resources in their offspring and are therefore more interested in their partner's personality and parenting resources. Accordingly, it can be assumed that the amount of an actor's own resources will also affect his or her mate preference. In contrast, in a low reproductive strategy, the amount of an individual's own resources may not affect the mate selection preference.

Life-history theory focuses on how individuals allocate time, resources, and energy effectively for survival and reproduction (Roff, 2001; Belsky, 2010; Dunkel et al., 2013); the process of allocation constitutes the life-history strategy. Life-history strategies can be divided into fast strategies and slow strategies. Fast strategies focus on offspring quantity, while slow strategies focus on offspring quality. Life-history theory holds that the main task of the entire life history of an individual is to balance resource allocation because resources are limited. In the process of resource allocation, two main investment directions are concerned, namely, physical investment and reproduction investment. Physical investment refers to individuals' use of resources to maintain their physical health and intellectual growth, while reproductive investment refers to individuals' use of resources for social activities related to reproduction, 
such as same-sex competition and raising offspring. As a key link in reproduction investment, mate selection is of course inseparable from the allocation of time and resources. Therefore, does the amount of resources that an individual can offer in a trade-off affect his or her preference regarding the characteristics of a mate? In fact, mate selection requirements change in response to changes in environmental cues (Roney, 2003; Janssens et al., 2011; Yong and Li, 2012), and the amount of resources that an individual possesses affects trade-offs in the process of mate selection.

Sexual strategies theory divides mate selection strategies into long-term and short-term sexual strategies from the perspective of evolutionary psychology. Long-term sexual strategies refer to mate selection strategies aimed at establishing long-term and stable sexual relationships, while short-term sexual strategies refer to a mate selection strategy aimed at establishing shortterm sexual relationships, such as one-night stands (Buss and Schmitt, 1993, 2016). These different sexual strategies have developed based on different adaptations of both sexes for the purpose of successful reproduction. In different sexual strategies, individuals have different preferences in mate selection. Individuals who adopt long-term sexual strategies pay more attention to resources and personality, and there are further differences between men and women. In contrast, individuals with short-term sexual strategies pay more attention to physical features, and there is no gender difference (Li, 2007). Studies have found that men prefer short-term partners, while women tend to seek long-term partners (Buss and Schmitt, 1993), but when women have more financial resources, their preference for short-term partners increases (Gangestad and Simpson, 2000). It can be inferred that individuals with fewer resources who adopt long-term sexual strategies will pay more attention to resource-related characteristics because they are in high demand, while individuals who adopt short-term sexual strategies may be less affected by their own resources in these circumstances.

\section{Society: The Optimal Match Perspective}

Complementarity theory (Winch, 1958) argues that when mate selection is manifested as a psychological need and personal motivation, individuals tend to refer to their own needs and choose a member of the opposite sex whose characteristics complement their own. Accordingly, Becker (1974) predicted that individuals with fewer financial resources would tend to choose mates with more financial resources, but later studies found the opposite (Lui and Suen, 1999). However, it was also found that women with fewer financial resources paid more attention to their partner's economic status (Vigil et al., 2006), while no such result was found for men (Chen and Yao, 2018). Therefore, there may be gender differences in resource complementarity.

Positive assortative mating theory (Buss, 1985) emphasizes that individuals choose partners with characteristics similar to their own. Therefore, individuals tend to choose a member of the opposite sex with similar values, socioeconomic status, and educational level (Watkins and Meredith, 1981; Lui and Suen, 1999; Deng et al., 2014). In the research on animal mating, the same matching principle has been found (Jiang et al., 2013).
The matching of biological characteristics can be explained from a genetic perspective, that is, the reduction of genetic variation (Alvarez and Jaffe, 2004). The matching of social characteristics is the result of socialization. Individuals of similar social and economic status have similar social living environments. Therefore, it is beneficial for them to find partners with matching social characteristics to facilitate adaption to a shared social life.

According to social exchange theory, mate selection is a process of seeking resource exchange (Edwards, 1969; Homans, 1974; Kieserling, 2019). This theory emphasizes that when making mate decisions, individuals are attracted to people who have the resources that they require. Stimulus-value-role theory also holds that the maintenance of romantic relationships is based on the fair exchange of resources between men and women (Murstein, 1980). That is, the amount of resources is a key influence on preference when choosing a mate. To better adapt to social life, individuals must consider the resource requirements for their partners according to the amount of their resources to achieve the best resource exchange and matching. For example, women with money resources pay less attention to men's money resources (Kasser and Sharma, 1999; Eagly et al., 2004) and, in contrast, raise their demands on men's economic resources (Chen and Yao, 2018).

Social learning theory (Hayes, 1995) argues that preference in mate selection is influenced by the social status of men and women and the power of socialization. In a patriarchal society, men are in a dominant socioeconomic position and have more choices in choosing a mate. Therefore, they have higher requirements regarding women's appearance. In such a context, women are in a relatively disadvantaged position, and thus, compared with men, it is more difficult for women to survive independently. Therefore, they tend to seek resourcerich men of their own socioeconomic status when choosing a mate, and they care much less about the physical features of men. Through learning this social reality, individuals develop different decision-making behaviors.

Similarly, the mate selection gradient theory emphasizes a matching method of "men seeking low and women seeking high," which reflects the influence of a large social structure on a small family structure. In fact, the mate selection decision behavior of individuals is the result of socialization, and individuals tend to choose the partner who represents the best social match. Specifically, men prefer women who are below them in, e.g., socioeconomic status or education level, to gain the dominant position in the family. In contrast, women are more likely to choose partners who are superior to them in economic ability, educational background, and other aspects (Wei, 2013). According to this theory, in the socialization process, people develop different gender role expectations regarding their partners, which affects how different individuals treat resources when selecting a mate. Therefore, the influence of the amount of resources of both men and women on preferences in mate selection should be reflected in different dimensions. Namely, this influence results in the difference between men who value appearance and women who value money. 
Based on such gender differences between men and women, Buss (1989) maintained that when women had more financial resources, the difference between women's preference for financial resources and men's preference for appearance would disappear. Later studies demonstrated that when women's financial resources increase, they pay less attention to their spouse's financial status (Eagly and Wood, 1999; Kasser and Sharma, 1999) and exhibit an increasing preference for physical attractiveness (Gangestad and Simpson, 2000). However, other researchers found that an increase in women's financial resources did not reduce their attention to their partners' financial resources (Townsend, 1989; Wiederman and Allgeier, 1992). Therefore, gender differences in the influence of resources on mate choice decisions are worthy of further research.

Therefore, resources play an important role in mate selection. Different individuals make different trade-offs and resource exchanges when making mate choice decisions and determine whether they improve the quality of future generations or enhance social adaptation. However, although early researchers contributed a substantial number of useful outcomes regarding the influence of resources on mate selection, they limited the studied resources to money, while neglecting the importance of time resources.

\section{Thinking: Optimal Decision-Making Perspective}

Mate selection is a complex decision-making process (Harte et al., 1994; Candolin, 2003; Liu et al., 2011). To achieve the purpose of mating, the process of choosing a mate is based on an analysis of information. At present, several theoretical models have been used to investigate the influence of the amount of resources on decision-making; this research is of substantial significance for us in examining the influence of the amount of resources on the decision-making behind mate selection. These theoretical models also provide insight into the effect of time resources on mate selection.

The attentional focus model notes that a lack of time resources will affect an individual's attention to the object and scope in the task environment and limit attention more to task-related factors (Karau and Kelly, 1992). The mate selection decision is a heuristic search process with limited rationality, and time urgency will affect the informationprocessing mode of the subjects with respect to mate selection cues (Liu et al., 2011). Individuals under high time pressure exhibit task focus, while non-task focus occurs if abundant time is available ( $\mathrm{Li}$ et al., 2015). Based on the definition of time resources in this paper, we assume that there is no essential difference in the significance of time resources for individuals between the mating decision task in the experiment and the mating decision in reality. Thus, according to the attention-focus model, we speculate that individuals who lack time pay more attention to the traits that they value most when making mate selection decisions because of the limited scope of the attention focus. In contrast, individuals with copious time pay more attention to a wider range of traits and have more diversified dimensions of cue preference when making mate selection decisions. Whether time resources play different roles in the experiment and the real mate selection decision process needs to be verified by future research.

According to the mindset theory, different resources activate different sets of thoughts. The introduction of money will activate the value maximization mindset of individuals, while the introduction of time will lead individuals to assume an emotional mindset (Liu and Aaker, 2008). The introduction of the concept of money leads individuals to pay more attention to the practical value of products and to pursue the maximization of their own economic interests, while the introduction of the concept of time creates a tendency among individuals to think about information related to personal meaning, such as emotions and experiences (Liu and Aaker, 2008; Mogilner and Aaker, 2009; Tong et al., 2013). According to this theory, it can be assumed that financial and time resources will activate different thinking patterns in the mate selection decision-making process, thereby influencing the preference of individuals in mate selection. Individuals stimulated by financial resources will pay more attention to the characteristics related to such resources when seeking value maximization, while individuals affected by time resources will pay more attention to the personality characteristics of a potential mate and the compatibility of their outlooks when emotions start to develop. Further experiments are required to test these claims.

The dual system action model for decision-making (Sloman, 1996; Kahneman and Frederick, 2002; Sun et al., 2007) divides the decision-making and reasoning systems into (1) a heuristic system based on intuition and (2) an analytical system based on rationality. When making decisions, an increase in time pressure caused by a lack of time resources will drive individuals to rely more on automatic and rapid heuristic strategies and reduce the use of slower but more comprehensive and effective analytical strategies (Saini and Monga, 2008; Li et al., 2016c). However, the amount of financial resources will affect how heavily individuals weigh their own resources (Hansen et al., 2013). In the decision-making process, individuals tend to employ a rational analysis process but engage in less emotional participation. Therefore, one can speculate that the cognitive changes caused by financial resources are influenced by the rational analysis system, while the emotional changes caused by time resources are driven by the heuristic system.

Nicieza and Metcalfe (1999) two-system priming model notes that there are two major subsystems in the decisionmaking process of individuals, specifically the hot system and the cold system. The hot system primarily refers to the emotional system, which is physiologically based on the amygdala and dominates emotion-driven behavior. The cold system is the cognitive system, which is physiologically based on the hippocampus and frontal lobes and governs rational, thoughtful, strategic, and planned behavior. A lack of time resources will make individuals feel anxiety and tension, which will affect their judgment in decision-making (DeVoe and Pfeffer, 2011; Young et al., 2012; Kocher et al., 2018), and the amount of financial resources will affect the individual's cognition of the decision-making situation and of the allocation and balance 
of resources (Hansen et al., 2013). Thus, we can infer that time resources mainly concern the hot system, while financial resources mainly concern the cold system.

Thus, time and financial resources influence mate selection decisions through different action mechanisms, namely, through cognitive channels (money) and through emotional channels (time).

\section{THEORETICAL CONCEPT OF THE INFLUENCE MECHANISMS}

The classical economic theory holds that the ideal decision proceeds from the rational evaluation and comparison of various options and that emotional factors can interfere with rational analysis and reduce the efficiency of decision-making; these factors can only play a negative role when we attempt to make optimal decisions. However, modern researchers believe that emotions are as important to decision-making as cognition (Olofsson et al., 2008; Pessoa, 2008; Quartz, 2009). Therefore, based on the preceding analysis, this paper describes a possible cognitive and emotional influence mechanism for financial and time resources with respect to cue preferences in mate selection decisions.

\section{Influence Mechanism of Financial Resources: Cognitive Dominance}

From the previous theoretical discussion, we can observe that financial resources affect individuals' perception of their own resources and self-worth and their cognition of a situation with respect to resource distribution and tradeoffs. That is, the amount of financial resources affects individuals' selfesteem, mate value, and sense of power. Specifically, the amount of financial resources affects individuals' cognition of their sense of self-wealth (Li et al., 2016a) and affects their self-esteem (Twenge and Campbell, 2016). In particular, an increase in financial resources will improve individuals' self-perceived mate value (Shackelford et al., 2005; Howie and Pomiankowski, 2018). The amount of financial resources also affects individuals' sense of power and control with respect to decision-making situations (Li et al., 2016b).

\section{Mediating Effect of Self-Esteem}

We assume that self-esteem plays a mediating role in the influence of financial resources on mate selection decisions. Specifically, the amount of financial resources can make individuals feel subjectively rich or poor (Nelson and Morrison, 2005; Li et al., 2016a). An individual's socioeconomic status is closely related to his/her level of self-esteem; when the individual's socioeconomic status is higher, the corresponding level of self-esteem is higher (Zhang and Postiglione, 2001; Chen et al., 2014; Twenge and Campbell, 2016). The amount of an individual's financial resources reflects his or her socioeconomic status to a certain extent. Thus, one can speculate that when an individual possesses more financial resources, the corresponding level of self-esteem is higher. An individual's level of self-esteem also affects his or her mate selection strategy, and this effect varies between genders (Kielser and Baral, 1970; Jiang and Gong, 2015). For example, men with different levels of self-esteem prefer women with different personalities (Gong, 2014).

\section{Mediating Effect of Mate Value}

There are good reasons to suppose that mate value plays a mediating role in the influence of financial resources on mate preference. Self-concept is an individual's subjective perception and judgment of his or her physiological state, personality, attitude, social role, past experience, and other aspects (Ling et al., 2016). Based on this definition, the subjective sense of wealth provided by financial resources is strongly related to self-concept, and mate value, as a basic part of self-concept, should also be influenced by such resources (Millar et al., 2019). Researchers have found that mate value has a significant predictive effect with respect to the mate selection strategy (Surbey and Brice, 2007; Zhang et al., 2016). The amount of financial resources that a man possesses is a positive predictor of his mate value (Shackelford et al., 2005), and individual self-perceived mate value has a significant impact on cue preferences in mate selection (Surbey and Brice, 2007; Back et al., 2011; Reeve et al., 2016). Therefore, it is reasonable to assume that mate value plays a mediating role in the influence of financial resources on cue preferences in mate selection.

\section{Mediating Effect of the Sense of Power}

One assumption is that the sense of power plays a mediating role in the relationship between financial resources and mate selection. For consumers, deprivation of financial resources reduces the sense of personal power and resource control (Li et al., 2016b), whereas high power leads individuals to raise their standards of mate selection. There are also gender differences in the influence of the sense of power on the mate selection decision. In the mate selection decision, women's standards for partner personality are not affected by power, but as men's sense of power increases, their demand for women's character qualities will increase significantly (Zheng and Chi, 2013; Laurin et al., 2016). These findings suggest that the sense of power is likely to be a mediating variable between financial resources and mate selection.

\section{Influencing Mechanism of Time Resources: Emotion Dominates}

Based on the previous theoretical analysis, time resources primarily influence the mate selection decision through the emotional path. Specifically, a lack of time resources will generate anxiety, fear, and other emotions that affect individuals' cue preferences in mate selection.

\section{Mediating Effect of Anxiety}

According to several empirical physiological studies, a lack of time resources will activate individuals' anxiety, thereby affecting the outcome of mate selection decisions. When time resources are lacking, an individual's emotional arousal sensitivity will 
be improved (Bland et al., 2016); time pressure will rapidly increase neuron functioning through corticosteroids and norepinephrine (Karst et al., 2005) and cause emotional activation, and individuals will be more likely to experience emotions, such as anxiety, that influence decision-making.

Regarding emotion and decision-making, neuroscience studies have found a high degree of overlap between the decisionrelated brain regions and the neural circuits of emotion, which may reflect the neural basis for emotion's effect on decisionmaking (Luo et al., 2012). The research on event-related potential also provides valuable information regarding the relationship between emotion and decision-making. Gehring and Bortfeldt (2002) recorded feedback-related negativity (FRN) located in the anterior gyrus of the cingulate belt in an economic decisionmaking game experiment. The anterior cingulate gyrus is closely related to emotional function and plays a crucial role in people's evaluation of behavior. This evaluation can affect expectations regarding the emotional experience caused by a decision or affect the emotional state at the time of the decision, which influence decision-making behavior. The same study also showed that individuals with high anxiety had lower FRN than people with low trait anxiety. A lack of time resources will result in the accumulation of negative emotions, such as individual anxiety, and affect decision-making through the emotional path (Li et al., 2016c). Mate selection is a complex decision-making process (Candolin, 2003). Therefore, we can assume that anxiety plays a mediating role in the influence of time resources on mate selection.

\section{Mediating Effect of Fear}

A lack of time resources may induce an individual's fear and affect the mate selection decision. When time resources are scarce, people experience a sense of pressure (Young et al., 2012; Li et al., 2015; Li, 2017). In a study on death threats, researchers found that activating individuals' deathrelated awareness, i.e., mortality salience, would shorten their perceived temporal extension, while individuals' fear of death was also significantly activated (Zhou, 2019) because of the time pressure caused by the shortened perceived lifetime. Therefore, time pressure may induce an unconscious fear of death. Regarding fear, researchers found that fear affects individuals' decision-making about risk and affects decisionmaking events with known and unknown probabilities in various ways (Bouffard, 2015; Wang, 2018; Yang et al., 2018). Fear also has a significant impact on individual trust decisions (Qiao et al., 2018). Therefore, the choice of a spouse can also be influenced by fear.

In the field of mate selection, although there is no study that directly measures the influence of individual fear emotions on mate selection decisions, several researchers have experimentally verified that the initiation of the threat of death can significantly affect the life-history strategy and mate selection criteria of individuals (Griskevicius et al., 2013; Laran and Salerno, 2013; Wang and Chen, 2016). According to life-history theory, individuals derive life-history strategies in the process of resource allocation (Belsky, 2010). The threat of death may induce the individual's fear by making that individual feel a lack of time resources, which affects the mate selection decision. Therefore, we hypothesized that fear plays a mediating role in the influence of time resources on mate selection.

\section{Interaction Between Cognition and Emotion}

According to the two-system priming model, in the decisionmaking process, the cold and hot systems generally work together but only because different stimuli will result in situations in which the cold and hot systems play a dominant role. Therefore, we believe that the influence mechanisms of monetary and temporal stimuli are not completely independent of one another. In fact, studies have found that monetary stimuli can affect individuals' anxiety (Ma et al., 2015), while temporal stimuli can affect individuals' cognitive judgment (Li et al., 2016c). In addition, cognition and emotion also interact (Ran, 2009; Barajas, 2015). Emotions influence individual decisionmaking by playing a motivational role (Song et al., 2010), and high self-esteem and a high sense of power can reduce individuals' anxiety (Gao, 2015; Zhang et al., 2018). In addition, high individual self-esteem helps alleviate fear (Harmon-Jones et al., 1997; Zhang and Zuo, 2006). Therefore, we assume that financial resources affect mate selection mainly through cognitive pathways, that time resources affect mate selection mainly through emotional pathways, and that cognitive pathways affect emotional pathways (Figure 1).

\section{RESEARCH PROSPECTS}

\section{Influence Mechanism of the Resource Amount on the Mate Selection Decision}

This paper reviews and draws lessons from the theoretical models related to the influence of resources on mate selection and finds that a large number of studies have focused on results rather than process. Although achievements have been made, the internal mechanism of this influence remains unclear, and the psychological process requires additional study. Regrettably, the research on resources is too narrowly focused and neglects the investigation of time resources. Therefore, based on the relevant theories, this paper makes several theoretical assumptions regarding the influence mechanism of resource availability on mate choice decisions (Figure 1).

We hypothesize that financial resources influence mate choice decisions primarily through the mediation of self-cognition (including self-esteem, mate value, and sense of power; see Figure 1, paths 1,2, and 3), whereas time resources influence mate choice decisions primarily through the mediation of emotions (including anxiety and fear; see Figure 1, paths 5, 6, and 7). The amount of financial resources will also affect individuals' emotional state (see Figure 1, path 4). Studies have found that more financial resources can alleviate the impact of negative emotions on individuals, particularly painful emotions (Zhou et al., 2009; Ma et al., 2015; Vohs, 2015). Self-cognition also affects emotion (see Figure 1, path 8). For example, high self-esteem can alleviate anxiety and fear (Harmon-Jones et al., 1997; Gao, 2015), and 


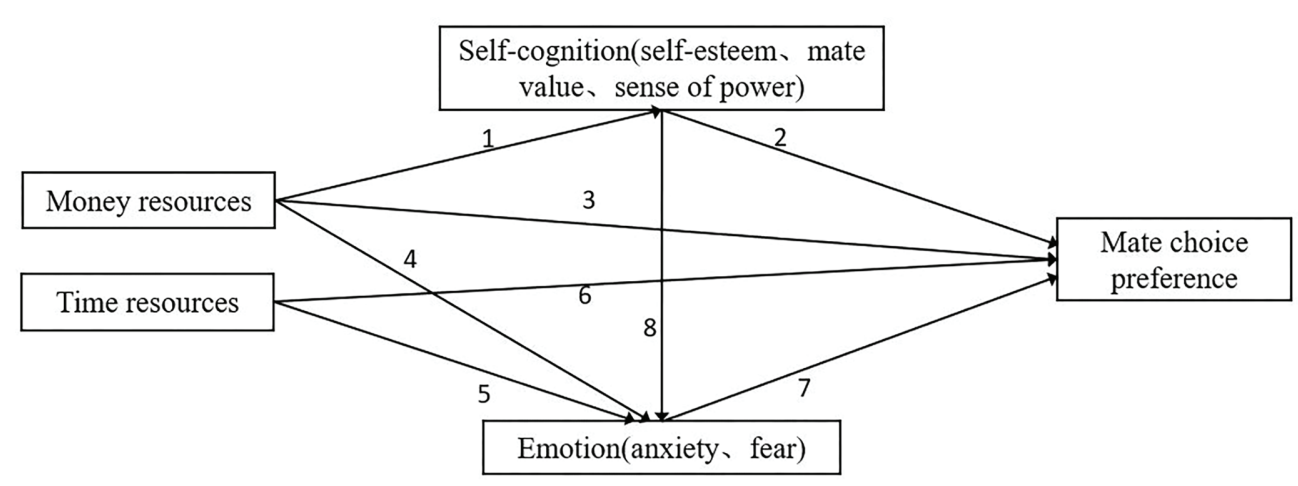

FIGURE 1 | Path diagram of resource influence on mate choice preference.

individuals with high power traits experience lower anxiety and depression (Zhang et al., 2018).

This paper summarizes previous studies and proposes the cognitive and emotional pathways of resource influence on the mate choice decision and the interaction between the two pathways. However, some areas that have not been elucidated in previous studies are still worth thinking about. For example, do money and time resources have different effects on the outcome of mate choice decisions because of different influencing mechanisms? Previous studies found that money resources can affect individuals' extent of preference for partners' economic status and appearance (Vigil et al., 2006; Laurin et al., 2016; Li et al., 2016a), whereas time resources can more significantly affect individuals' thinking on the number of dimensions of partner characteristics (Liu et al., 2011; Li et al., 2016d). Therefore, are the effects of money and time resources on mate selection decisions reflected in the degree and dimension of preferences, respectively? In addition, previous studies found the impact of money resources on emotions (Ma et al., 2015); however, no studies exist on the impact of time resources on individual self-cognition. Will time resources affect individuals' perception of their value? This area of concern remains for future research.

\section{Long-Term and Short-Term Strategies for Mate Selection}

Life-history theory divides life-history strategies into fast and slow strategies (Belsky, 2010; Dunkel et al., 2013). Individuals with different life-history strategies tend to choose different mating strategies. Individuals who adopt the fast strategy may be inclined to choose the short-term sexual strategy to obtain more mating opportunities, while individuals who adopt the slow strategy are more likely to choose the long-term sexual strategy to ensure offspring quality. The amount of money and time resources will then affect the preferences of individuals with different mate selection strategies (Gangestad and Simpson, 2000; Vigil et al., 2006).

Previous research on the influence of resources on mate selection has produced inconsistent conclusions due to the lack of a clear distinction between long-term and short-term mate selection. By reviewing previous studies, it was found that most of the literature on the influence of resources on mate selection begins with long-term mate selection and that the amount of men's financial resources was not relevant to their requirements regarding the resource acquisition ability and beauty of potential partners (Wiederman and Allgeier, 1992). However, without clearly distinguishing between shortand long-term mate selection, other studies found that an increase in financial resources will lead men to increase their requirements regarding the appearance of their partners (Yong and Li, 2012; Li et al., 2016a). Regarding women's choice of a spouse, with respect to long-term spouse selection, studies have found that an increase in financial resources will lead women to pay more attention to the economic status of their partner (Townsend, 1989; Khallad, 2005), and several studies have noted that an increase in monetary resources will reduce a woman's demand for male economic resources (Kasser and Sharma, 1999; Eagly et al., 2004) and increase her requirements with respect to male appearance (Gangestad and Simpson, 2000). Women with low financial resources, however, pay more attention to the financial resources of the opposite sex (Chen and Yao, 2018) and commitment under the condition of longterm mate selection (Vigil et al., 2006), while they value both appearance and money in short-term mate selection (Vigil et al., 2006). Because of these inconsistent conclusions, it is necessary to distinguish long-term from short-term mate selection in the process of studying the influence of resources on the mate selection decision and thus clarify the inconsistencies in recent research conclusions.

\section{Cultural Background}

Evolutionary psychologists believe that culture does not influence mate preferences because of "universal human nature." Buss (1989) studied the individual's mate preference in 37 cultures and found gender differences in women's preference for economic resources and men's preference for appearance, and the gender difference was consistent across cultures. According to the social learning theory, the individual's mate preference is acquired during the socialization process; therefore, different social cultures affect the individual's mate preference. 
The study points out that Chinese people pay more attention to family-related conditions and traits when choosing a spouse, whereas Americans pay more attention to the fit of religion and values (Yue et al., 2005; Pan, 2018), and the age space for Americans to choose a spouse is significantly greater than that for Chinese people (Yue et al., 2005). Some studies suggested that mate choice cues can be divided into "necessities" and "luxuries." Individuals value "necessities" (such as physical attractiveness) under the condition of fewer resources and consider "luxuries" (such as creativity) under the condition of more resources (Li et al., 2002; Chen and Yao, 2018). This has been found in both China and the United States; however, the definition of "necessities" in mate preference is different in these two cultures. Chinese subjects rated loyalty and health more as "necessities," whereas American subjects rated intelligence, physical appearance, and economic resources as "necessities." Therefore, the influence of culture is not as extreme, and future research into cultural contexts may be able to strike a balance between evolutionary and social perspectives.

In addition, this influence from culture may change as a result of social development. For example, a study of Israelis' and Americans' mate preferences found that Israelis value physical appearance more than Americans-a reversal from the study by Buss et al. a decade ago (Buss et al., 1990; Hetsroni, 2000). Some studies (Yue et al., 2005; Chen et al., 2012) also found that the gender gap in mate preference of Americans is smaller than that of the Chinese, and the gender role pattern in mate choice is gradually becoming more neutral. Moreover, American subjects generally require less financial resources from their partners and attach greater importance to spiritual traits (Yue et al., 2005; Pan, 2018). That is to say, the importance of economic resources for American subjects is decreasing. Whether this is because of different economic levels or cultural backgrounds remains to be further discussed. In recent years, little research has been done in this field on cultural background. Under the background of current world social development, of great theoretical significance is to study the role of culture in the influence of resources on mate selection decisions.

\section{Gender Differences and the Actor-Partner Effect}

Based on previous studies, there is a gender difference in the influence of individual resources on mate choice decisions. According to parental investment theory, sexual strategy theory, complementarity theory, social learning theory, and mate selection gradient theory, men and women prefer different characteristics in the process of mate selection decisions, and the amount of resources may have different dimensions of influence on men and women. In the case of fewer financial resources, women attach more importance to the economic status of partners in long-term mate selection, while men attach more importance to the fidelity of women (Chen and Yao, 2018). Regardless of the long- or short-term conditions for mate selection, with an increase in financial resources, men will increase their requirements regarding the physical appearance of their partners (Wiederman and Allgeier, 1992; Li et al., 2016a), while women value economic conditions, appearance and character (Wiederman and Allgeier, 1992; Gangestad and Simpson, 2000; Lu et al., 2015). Therefore, we should take note of gender differences in investigating the influence mechanism of resources.

The matching feature of gender is also a topic worth studying. When discussing the influence mechanism of the amount of resources on the decision of choosing a partner, we should pay attention to the particularity of the research object and discuss the mutual influence between men and women, i.e., the actor-partner effect in statistics. More specifically, the actor-partner effect includes the actor effect, which refers to the effect of individuals on their own outcome variables, and the partner effect, which refers to the effect of individuals on the outcome variables of the other party in the paired relationship (Cook and Kenny, 2005; Kenny and Ledermann, 2010). According to the positive assortative mating theory, individuals tend to seek individuals with characteristics similar to their own, such as their cultural and educational background and social and economic status, which may be influenced by certain gender matching factors, while the research object of mate selection itself is characterized

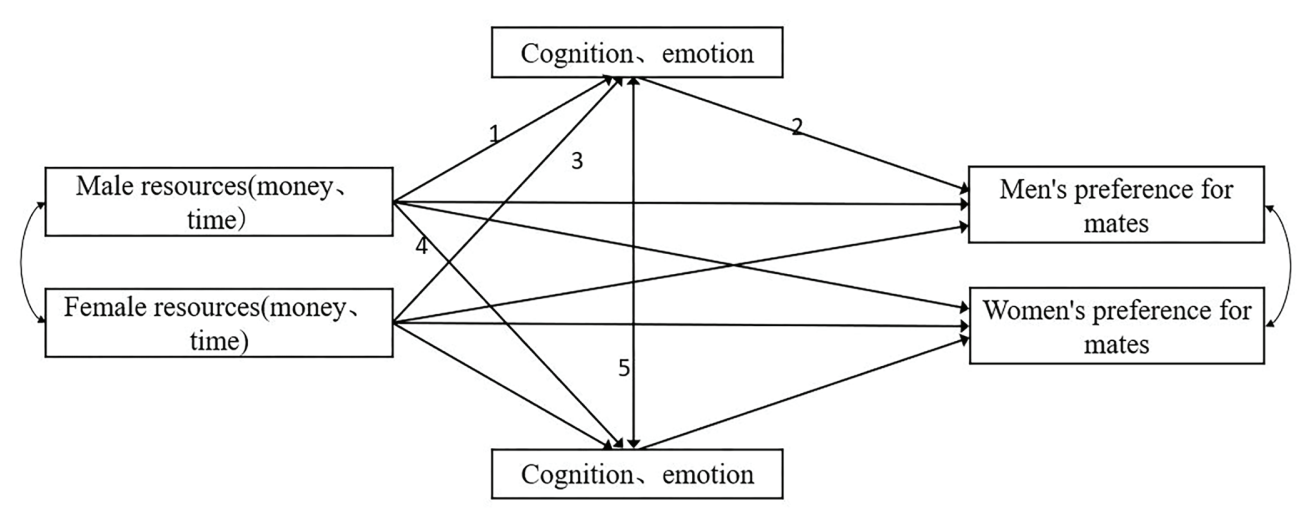

FIGURE 2 | Male and female gender actor-partner effect model of the influence of monetary resources on mate choice preference. 
by paired matching. The matching characteristics of the research objects make the data provided by individuals in the paired relationship nonindependent; thus, the characteristics of one individual may affect the relevant characteristics of the other (Cook and Kenny, 2005).

For example, resources influencing the mate selection decision through cognition and emotion (see Figure 2, paths 1, 2, and 3), during the process, a male with more resources is subject to cognitive or emotional factors that affect his mate choice decisions and the match of women (as shown in Figure 2, paths 4 and 2). Will women's cognition or emotion affect men's cognition and emotion and thus affect men's choice of a mate (see Figure 2, paths 5 and 2)? In view of the matching characteristics of males and females, it is necessary to examine the actor-partner effect on the influence mechanism.

\section{REFERENCES}

Alvarez, L., and Jaffe, K. (2004). Narcissism guides mate selection: humans mate assortatively, as revealed by facial resemblance, following an algorithm of "self seeking like". Evol. Psychol. 2, 177-194. doi: 10.1177/147470490400200123

Back, M. D., Penke, L., Schmukle, S. C., and Asendorpf, J. B. (2011). Knowing your own mate value: sex-specific personality effects on the accuracy of expected mate choices. Psychol. Sci. 22, 984-989. doi: 10.1177/0956797611414725

Barajas, M. (2015). Thinking and feeling: the influence of positive emotion on human cognition. Hilltop Rev. 7, 3-11.

Becker, G. (1974). "Economics of the family: marriage, children, and human capital" in A theory of marriage. ed. T. W. Schultz (University of Chicago Press), 299-351.

Belsky, J. (2010). Childhood experience and the development of reproductive strategies. Psicothema 22, 28-34.

Belsky, J., Steinberg, L., and Draper, P. (1991). Childhood experience, interpersonal development, and reproductive strategy: an evolutionary theory of socialization. Child Dev. 62, 647-670.

Bland, C., Howe, M., and Knott, L. (2016). Discrete emotion-congruent false memories in the DRM paradigm. Emotion 16, 611-619. doi: 10.1037/emo0000153

Bouffard, J. A. (2015). Examining the direct and indirect effects of fear and anger on criminal decision making among known offenders. Int. J. Offender Ther. Comp. Criminol. 59, 1385-1408. doi: 10.1177/0306624X14539126

Buss, D. (1985). Human mate selection. Am. Sci. 73, 47-51.

Buss, D. M. (1989). Sex differences in human mate preferences: evolutionary hypotheses tested in 37 cultures. Behav. Brain Sci. 12, 1-14. doi: 10.1017/ s0140525x00023992

Buss, D. M., Abbott, M., Angleitner, A., Asherian, A., Biaggio, A., Blanco-Villasenor, A., et al. (1990). International preferences in selecting mates: a study of 37 cultures. J. Cross-Cult. Psychol. 21, 5-47. doi: 10.1177/002202 2190211001

Buss, D., and Schmitt, D. (1993). Sexual strategies theory: an evolutionary perspective on human mating. Psychol. Rev. 100, 204-232. doi: $10.1037 / 0033-295 X .100 .2 .204$

Buss, D., and Schmitt, D. (2016). "Sexual strategies theory" in Encyclopedia of evolutionary psychological science. eds. T. K. Shackelford and V. A. WeekesShackelford (Springer International Publishing AG), 1-5.

Candolin, U. (2003). The use of multiple cues in mate choice. Biol. Rev. Camb. Philos. Soc. 78, 575-595. doi: 10.1017/S1464793103006158

Chang, L., Wang, Y., Shackelford, T. K., and Buss, D. M. (2011). Chinese mate preferences: cultural evolution and continuity across indicates a quarter of a century. Personal. Individ. Differ. 50, 678-683. doi: 10.1016/j.aid. 2010.12.016

Chen, Y., Cheng, G., Guan, Y., and Zhang, D. (2014). The mediating effects of subjective social status on the relations between self-esteem and socioeconomic status for college students. Psychol. Dev. Educ. 30, 594-600 (in Chinese).

Chen, H., Liu, Y., and Yue, G. (2012). Sino-American college students' relative preferences for ideal partners. Dept. Soc. Psychol. 18, 195-203 (in Chinese). doi: 10.3969/j.issn.1006-6020.2012.03.001

\section{AUTHOR CONTRIBUTIONS}

$\mathrm{JH}$ analyzed and reviewed the literature, revised each draft, and completed the final approval of the version. XF supervised this study, revised each draft, and completed the final approval of the version. TS analyzed and reviewed the literature and revised each draft. All authors contributed to the article and approved the submitted version.

\section{FUNDING}

This study was supported by the Philosophy and Social Science Program in Anhui Province and the National Natural Science Foundation of China's programs (31971017; 31571157).

Chen, Y., and Yao, M. (2018). Influence of resource availability on college students' preference for mate cues. Psychol. Sci. 41, 674-679 (in Chinese).

Cook, W., and Kenny, D. (2005). The actor-partner interdependence model: a model of bidirectional effects in developmental studies. Int. J. Behav. Dev 29, 101-109. doi: 10.1080/01650250444000405

Deng, L., Dai, L., and Fang, X. (2014). Relationship between similarity of values, communication patterns and marital quality in couples. Stud. Psychol. Behav. 12, 231-237 (in Chinese).

DeVoe, S. E., and Pfeffer, J. (2007). When time is money: the effect of hourly payment on the evaluation of time. Organ. Behav. Hum. Decis. Process. 104, 1-13. doi: 10.1016/j.oBHDP.2006.05.003

DeVoe, S. E., and Pfeffer, J. (2011). Time is tight: how higher economic value of time increases feelings of time pressure. J. Appl. Psychol. 96, 665-676. doi: 10.1037/a0022148

Dillon, H. M., Adair, L. E., Wang, Z., and Johnson, Z. (2013). Slow and steady wins the race: life history, mate value, and mate settling. Personal. Individ. Differ. 55, 612-618. doi: 10.1016/j.aid.2013.05.015

Dunkel, C. S., Mathes, E., and Beaver, K. M. (2013). Life history theory and the general theory of crime: life expectancy effects on low self-control and criminal intent. J. Soc. Evol. Cult. Psychol. 7, 12-23. doi: 10.1037/h00 99177

Durante, K. M., Griskevicius, V., Simpson, J. A., Cantu, S. M., and Tybur, J. M. (2012). Sex ratio and women's career choice: does a scarcity of men lead women to choose briefcase over baby? J. Pers. Soc. Psychol. 103, 121-134. doi: $10.1037 / \mathrm{a} 0027949$

Eagly, A. H., and Wood, W. (1999). The origins of sex differences in human behavior: evolved dispositions versus social roles. Am. Psychol. 54, 408-423. doi: 10.1037/0003-066X.54.6.408

Eagly, A. H., Wood, W., and Johannesen-Schmidt, M. C. (2004). "Social role and found of sex differences and similarities: implications for the partner preferences of women and men" in Psychology of gender. 2nd Edn. ed. S. Hartman (New York, NY, US: Guilford Press), 269-295.

Edwards, J. (1969). Familial behaviors as social exchange. J. Marriage Fam. 31, 518-526. doi: 10.2307/349775

Gangestad, S. W., and Simpson, J. A. (2000). The evolution of human mating: trade - offs and strategic of pluralism. Behav. Brain Sci. 23, 573-587. doi: 10.1017/S0140525X0000337X

Gao, L. (2015). Attributional bias of self-esteem and its effects on state anxiety. Chin. J. Clin. Psychol. 23, 818-821 (in Chinese). doi: 10.16128/j.cnki.10053611.2015.05.014

Gehring, H., and Bortfeldt, A. (2002). A parallel genetic algorithm for solving the container loading problem. Int. Trans. Oper. Res. 9, 497-511. doi: $10.1111 / 1475-3995.00369$

Gino, F., and Mogilner, C. (2014). Time, money, and morality. Psychol. Sci. 25, 414-421. doi: 10.1177/0956797613506438

Gong, Y. (2014). Relationship between self-esteem, values and unmarried men's preference in mate selection. (master), Nanjing Normal University, Available from Cnki (in Chinese). doi: 10.7666/d.Y2624155 
Griskevicius, V., Ackerman, J. M., Cantu, S. M., Delton, A. W., Robertson, T. E., Simpson, J. A., et al. (2013). When the economy falters, do people spend or save? Responses to the resource scarcity depend on childhood environments. Psychol. Sci. 24, 197-205. doi: 10.1177/0956797612451471

Hansen, J., Kutzner, F., and Wanke, M. (2013). Money and thinking: reminders of money trigger abstract construal and shape consumer judgments. J. Consum. Res. 39, 1154-1166. doi: 10.1086/667691

Harmon-Jones, E., Simon, L., Greenberg, J., Pyszczynski, T., Solomon, S., and McGregor, H. (1997). Terror management theory and self-esteem: evidence that increased self-esteem reduces mortality salience effects. J. Pers. Soc. Psychol. 72, 24-36. doi: 10.1037/0022-3514.72.1.24

Harte, J., Westenberg, M., and Someren, M. (1994). Process models of decision making. Acta Psychol. 87, 95-120. doi: 10.1016/0001-6918(94)90046-9

Hayes, A. (1995). The age preferences for same - and opposite-sex partners. J. Soc. Psychol. 135, 125-133. doi: 10.1080/00224545.1995.9711415

Hershfield, H. E., Mogilner, C., and Barnea Wrote, U. (2016). People who choose time over money are happier. Soc. Psychol. Personal. Sci. 7, 697-706. doi: $10.1177 / 1948550616649239$

Hetsroni, A. (2000). Choosing a mate in television dating games: the influence of setting, culture, and gender. Sex Roles 42, 83-106. doi: 10.1023/A:10 07084211572

Homans, G. (1974). Social behavior: Its elementary forms. Westdeutscher Verlag GmbH.

Howie, J. M., and Pomiankowski, A. (2018). "Mate value" in Encyclopedia of evolutionary psychological science. eds. T. K. Shackelford and V. A. WeekesShackelford (Cham: Springer International Publishing), 1-8.

Janssens, K., Pandelaere, M., Van den Bergh, B., Millet, K., Lens, I., and Roe, K. (2011). Can buy me love: mate attraction goals lead to perceptual readiness for status products. J. Exp. Soc. Psychol. 47, 254-258. doi: 10.1016/j. jesp.2010.08.009

Jiang, Y., Bolnick, D. I., and Kirkpatrick, M. (2013). Assortative mating in animals. Am. Nat. 181, e125-e138. doi: 10.1086/670160

Jiang, J., and Gong, Y. (2015). Research on unmarried men's preference in mate selection: traits, trends and influencing factors. J. Youth Stud. 3, 58-65+95-96 (in Chinese).

Kahneman, D., and Frederick, S. (2002). Representativeness revisited: Attribute substitution in intuitive judgment. Cambridge: Cambridge University Press, 49-81.

Karau, S., and Kelly, J. (1992). The effects of time scarcity and time abundance on group performance quality and interaction process. J. Exp. Soc. Psychol. 28, 542-571. doi: 10.1016/0022-1031(92)90045-L

Karst, H., Berger, S., Turiault, M., Tronche, F., Schutz, G., and Joels, M. (2005). Mineralocorticoid receptors are indispensable for nongenomic modulation of hippocampal glutamate transmission by corticosterone. Proc. Natl. Acad. Sci. U. S. A. 102, 19204-19207. doi: 10.1073/pnas.0507572102

Kasser, T., and Sharma, Y. S. (1999). Reproductive freedom, educational equality, and social preference for resource-acquisition characteristics in mates. Psychol. Sci. 10, 374-377. doi: 10.1111/1467-9280.00171

Kenny, D., and Ledermann, T. (2010). Detecting, measuring, and testing dyadic patterns in the actor-partner interdependence model. J. Fam. Psychol. 24, 359-366. doi: 10.1037/a0019651

Khallad, Y. (2005). Mate selection in Jordan: the effects of sex, socio - economic status, and culture. J. Soc. Pers. Relat. 22, 155-168. doi: 10.1177/0265407505050940

Kielser, S., and Baral, R. (1970). The search for a romantic partner: The effects of self - esteem and physical attractiveness on romantic behaviors.

Kieserling, A. (2019). "Blau (1964): exchange and power in social life" in Schlüsselwerke der Netzwerkforschung. eds. M. Gröhn and A. Lutz (Springer Fachmedien Wiesbaden GmbH), 51-54.

Kocher, M., Schindler, D., Trautmann, S., and Xu, Y. (2018). Risk, time pressure, and selection effects. Exp. Econ. 22, 216-246. doi: 10.1007/s10683-018-9576-1

Laran, J., and Salerno, A. (2013). Life - history strategy, the food choice, and caloric consumption. Psychol. Sci. 24, 167-173. doi: 10.1177/0956797612 450033

Laurin, K., Fitzsimons, G. M., Finkel, E. J., Carswell, K. L., VanDellen, M. R., Hofmann, W., et al. (2016). Power and the pursuit of a partner's goals. J. Pers. Soc. Psychol. 110, 840-868. doi: 10.1037/pspi0000048

Leclerc, F., Schmitt, B. H., and Dube, L. (1995). Waiting time and decision making: is time like money? J. Consum. Res. 22, 22, 110-119. doi: 10.1086/209439
Li, T. (2007). Mate preference necessities in long- and short-term mating: people prioritize in themselves what their mates prioritize in them. Acta Psychol. Sin. 39, 528-535 (in Chinese).

Li, Y. (2017). The influence of time stress and emotion on the false memory. (master), Hunan Normal University, Available from Cnki (in Chinese).

Li, N. P., Bailey, J. M., Kenrick, D. T., and Linsenmeier, J. A. W. (2002). The necessities and luxuries of mate preferences: testing the tradeoffs. J. Pers. Soc. Psychol. 82, 947-955. doi: 10.1037/0022-3514.82.6.947

Li, J., and Huang, X. (2013). The relationship between time and happiness: based on the comparison between their relationships with money and happiness. J. Southwest Univ. 39, 76-82+174 (in Chinese).

Li, M. Y., Li, J., Chan, D., and Zhang, B. (2016a). When love meets money: priming the possession of money influences mating strategies. Front. Psychol. 7:387. doi: 10.3389/fpsyg.2016.00387

Li, A., Luo, Y., and Li, B. (2016b). Does "money priming” make people rational or irrational?-- money priming and consumers' behavior decision-making. Foreign Econ. Manag. 38, 100-112 (in Chinese). doi: 10.16538/j.cnki.fem.2016. 06.007

Li, A., Sun, H., Xiong, G., Wang, X., and Li, B. (2016c). The effect and cognitive mechanism of "time poverty" on intertemporal choice and proactive behavior. Adv. Psychol. Sci. 24, 874-884 (in Chinese). doi: 10.3724/SP.J.1042.2016. 00874

Li, L., Xu, C., and Wang, L. (2016d). Males' Cue preference and information processing mode in mate-selection decision. J. Youth Stud. 39-48+95 (in Chinese).

Li, A., Yan, L., Wang, X., Ma, X., and Li, F. (2015). The double-edged effect and mechanism of time pressure. Adv. Psychol. Sci. 23, 1627-1636 (in Chinese). doi: 10.3724/SP.J.1042.2015.01627

Ling, H., Xia, Y., Zhang, J., Zhu, A., Zhong, N., Yang, Z., et al. (2016). The framework and development of self-concept. Chin. J. Clin. Psychol. 24, 363-367+337 (in Chinese). doi: 10.16128/j.cnki.1005-3611.2016.02.041

Liu, W., and Aaker, J. (2008). The happiness of giving: the time-ask effect. J. Consum. Res. 35, 543-557. doi: 10.1086/588699

Liu, Y., Su, L., and Wang, H. (2011). Women's cue preferences and information processing mode in mate choice. Acta Psychol. Sin. 43, 21-29 (in Chinese).

Lu, H. J., Zhu, X. Q., and Chang, L. (2015). Good genes, good providers, and good fathers: economic development involved in how women select a mate. Evol. Behav. Sci. 9, 215-228. doi: 10.1037/ebs0000048

Lui, H. -K., and Suen, W. (1999). A direct test of the efficient marriage market hypothesis. Econ. Inq. 37, 29-46. doi: 10.1111/j.1465-7295.1999. tb01414.x

Luo, Y., Wu, T., and Gu, R. (2012). Studies on neural correlates of emotion and cognition. Bull. Chin. Acad. Sci. 27, 31-41. (in Chinese).

Ma, Q., Hu, Y., Pei, G., and Xiang, T. (2015). Buffering effect of money priming on negative emotions - an ERP study. Neurosci. Lett. 606, 77-81. doi: 10.1016/j.eulet. 2015.08.048

Millar, M. G., Westfall, R. S., and Walsh, M. (2019). The moderating effects of mate-value on the relationship between perceived sex ratio and mating strategies. Personal. Individ. Differ. 145, 39-43. doi: 10.1016/j.aid.2019. 03.019

Mogilner, C., and Aaker, J. (2009). "The time vs. money effect": shifting product attitudes and decisions through personal connection. J. Consum. Res. 36, 277-291. doi: 10.1086/597161

Mogilner, C., and Norton, M. I. (2016). Time, money, and happiness. Curr. Opin. Psychol. 10, 12-16. doi: 10.1016/j.copsyc.2015.10.018

Murstein, B. (1980). Mate selection in the 1970s. J. Marriage Fam. 42, 777-792. doi: $10.2307 / 351824$

Nelson, L., and Morrison, E. (2005). The symptoms of resource scarcity. Psychol. Sci. 16, 167-173. doi: 10.1111/j.0956-7976.2005.00798.x

Nicieza, A. G., and Metcalfe, N. B. (1999). Costs of rapid growth: the risk of aggression is higher for fast-growing salmon. Funct. Ecol. 13, 793-800. doi: 10.1046/j.1365-2435.1999.00371.x

Olofsson, J. K., Nordin, S., Sequeira, H., and Polich, J. (2008). Affective picture processing: an integrative review of ERP findings. Biol. Psychol. 77, 247-265. doi: $10.1016 /$ j.biopsycho.2007.11.006

Pan, L., (2018). A comparative study of Chinese and American mate preferences from a cross-cultural perspective. Zhejiang University, Available from Cnki (in Chinese). 
Pessoa, L. (2008). On the relationship between emotion and cognition. Nat. Rev. Neurosci. 9, 148-158. doi: 10.1038/nrn2317

Qiao, Q., Yin, X., and Zhu, H. (2018). The impact of fear and anger on trust decision making. J. Bingtuan Edu. Inst. 28, 25-28 (in Chinese). doi: 10.3969/j. issn.1009-1548.2018.05.005

Quartz, S. R. (2009). Reason, emotion and decision-making: risk and reward computation with feeling. Trends Cogn. Sci. 13, 209-215. doi: 10.1016/j. tics.2009.02.003

Ran, H. (2009). The influence of emotion on cognition. Psychol. Res. 2, 28-33.

Reeve, S., Kelly, K., and Welling, L. (2016). The effect of mate value feedback on women's mating aspirations and mate preference. Personal. Individ. Differ. 115, 77-82. doi: 10.1016/j.paid.2016.06.007

Roff, D. (2001). "Life history, evolution of" in Encyclopedia of biodiversity. Vol. 132. ed. S. A. Levin (Academic Press), 715-728.

Roney, J. R. (2003). The effects of visual exposure to the opposite sex: cognitive aspects of mate attraction in human males. Personal. Soc. Psychol. Bull. 29, 393-404. doi: 10.1177/0146167202250221

Saini, R., and Monga, A. (2008). How i decide to decide on what i spend: use of heuristics is greater for time than for money. J. Consum. Res. 34, 914-922. doi: 10.1086/525503

Shackelford, T. K., Schmitt, D. P., and Buss, D. M. (2005). Universal dimensions of human mate preferences. Personal. Individ. Differ. 39, 447-458. doi: 10.1016/j.paid.2005.01.023

Sloman, A. S. (1996). Empirical case for two systems of reasoning. Psychol. Bull. 119, 3-22. doi: 10.1037/0033-2909.119.1.3

Song, L., Li, Y., and Liu, R. (2010). Influence of emotions and cognitive styles on decision-making. Chin. J. Clin. Psychol. 1, 120-122 (in Chinese).

Sun, Y., Li, S., and Yin, X. (2007). Two systems in decision-making and reasoning: heuristic system and analytic system. Adv. Psychol. Sci. 15, 721-726 (in Chinese). doi: 10.3969/j.issn.1671-3710.2007.05.001

Surbey, M. K., and Brice, G. R. (2007). Presupposition of male mate selection strategy change: self-perceived mate value increase (English). Acta Psychol. 3, 513-522.

Svenson, O. (1996). The decision making and the search for fundamental psychological regularities: what can be learned from a process perspective? Organ. Behav. Hum. Decis. Process. 65, 252-267. doi: 10.1006/obhd. 1996.0026

Tian, Q., Zhang, L., and Sun, S. (2019). The impact of economic status on female mating preferences from the perspective of evolutionary psychology. J. Psychol. Sci. 42, 681-687 (in Chinese). doi: 10.16719/j.cnki.1671-6981. 20190325

Tong, L., Zheng, Y., and Zhao, P. (2013). Is money really the root of all evil? The impact of priming money on consumer choice. Mark. Lett. 24, 119-129. doi: 10.1007/s11002-013-9224-7

Townsend, J. M. (1989). Mate selection criteria: a pilot study. Ethol. Sociobiol. 10, 241-253. doi: 10.1016/0162-3095(89)90002-2

Trivers, R. L. (1972). "Parental investment and sexual selection" in Sexual Selection and the Descent of Man. Aldine Publishing Company, 1881-1971, 136-179.

Twenge, M. J., and Campbell, W. K. (2016). The self-esteem and socioeconomic status: a meta-analytic review. Personal. Soc. Psychol. Rev. 6, 59-71. doi: 10.1207/s15327957pspr0601_3

Vigil, J., Geary, D., and Byrd-craven, J. (2006). Trade-offs in low-income women's mate preferences wire-sex differences in reproductive strategy. Hum. Nat. 17, 319-336. doi: 10.1007/s12110-006-1012-0

Vohs, K. D. (2015). Money priming can change people's thoughts, feelings, motivations, and behaviors: an update on 10 years of experiments. J. Exp. Psychol. Gen. 144, e86-e93. doi: 10.1037/xge0000091

Wang, L. (2018). The impact of fear on risk decision making. (master), The Fourth Military Medical University, Available from Cnki (in Chinese).
Wang, J., and Chen, B. (2016). The influence of childhood stress and mortality threat on mating standards. Acta Psychol. Sin. 48, 857-866 (in Chinese). doi: 10.3724/SP.J.1041.2016.00857

Watkins, M., and Meredith, W. (1981). Spouse similarity in newlyweds with new one to specific cognitive abilities, socioeconomic status, and education. Behav. Genet. 11, 1-21. doi: 10.1007/BF01065824

Wei, D. (2013). The study on senior intellectual women's personality characteristic of androgyny and the relationship with mate selection preference. (master), Shenyang Normal University, Available from Cnki (in Chinese). doi: 10.7666/d. D362095

Wiederman, M., and Allgeier, E. (1992). Gender differences in mate selection criteria: sociobiological or socioeconomic explanation? Ethol. Sociobiol. 13, 115-124. doi: 10.1016/0162-3095(92)90021-u

Winch, R. F. (1958). Mate-selection: A study of complementary needs. New York: Harper. 19-25.

Yang, Q., Zhao, D., Wu, Y., Tang, P., Gu, R., and Luo, Y. J. (2018). Differentiating the influence of incidental anger and fear on risk decision - making. Physiol. Behav. 184, 179-188. doi: 10.1016/j.hysbeh.2017.11.028

Yong, J. C., and Li, N. P. (2012). Cash in hand, want better looking mate: significant resource cues raise men's mating standards. Personal. Individ. Differ. 53, 55-58. doi: 10.1016/j.paid.2012.02.018

Young, D. L., Goodie, A. S., Hall, D. B., and Wu, E. (2012). Decision making under time pressure, modeled in a prospect and found framework. Organ. Behav. Hum. Decis. Process. 118, 179-188. doi: 10.1016/j.obhdp.2012.03.005

Yue, G., Chen, H., and Zhang, Y. (2005). Verification of evolutionary hypothesis on human mate selection mechanism in cross-culture context. Acta Psychol. Sin. 37, 561-568 (in Chinese).

Zhang, L., Liu, S., Li, Y., and Ruan, L. (2016). Long-run effect of heterosexual rejection on mating behavior for college students: based on the sociometer theory. J. Psychol. Sci. 39, 131-136 (in Chinese). doi: 10.16719/j. cnki.1671-6981.20160120

Zhang, S., Luo, K., Chen, Y., Luo, F., and Zhong, Y. (2018). Effects of power on anxiety and depression. Chin. J. Clin. Psychol. 26, 220-225+238 (in Chinese). doi: 10.16128/j.cnki.1005-3611.2018.02.003

Zhang, L. -F., and Postiglione, G. (2001). Thinking styles, self-esteem, and socio-economic status. Personal. Individ. Differ. 31, 1333-1346. doi: 10.1016/ s0191-8869(00)00227-0

Zhang, Y., and Zuo, B. (2006). Self-esteem terror management theory. Adv. Psychol. Sci. 4, 273-280 (in Chinese). doi: 10.3969/j.issn.1671-3710.2006.02.021

Zhao, Q. (2015). The study on the sunk cost of time and money and its relationship with relevant factors. (master), Jinan University, Available from Cnki (in Chinese). doi: CNKI:CDMD:2.1015.977602

Zheng, K., and Chi, Y. (2013). The Influence of power in mate preference. Paper presented at The 16th National Academic Congress of Psychology, Nanjing, Jiangsu, China (in Chinese).

Zhou, J. (2019). Research on death threat and defense mechanisms of cancer patients. (Ph.D.), Southwest University, Available from Cnki (in Chinese).

Zhou, X., Vohs, K., and Baumeister, R. (2009). The symbolic power of money reminders of money alter social distress and physical pain. Psychol. Sci. 20, 700-706. doi: 10.1111/1467-9280.2009.02353.x

Conflict of Interest: The authors declare that the research was conducted in the absence of any commercial or financial relationships that could be construed as a potential conflict of interest.

Copyright (c) $2020 \mathrm{Hou}$, Shu and Fang. This is an open-access article distributed under the terms of the Creative Commons Attribution License (CC BY). The use, distribution or reproduction in other forums is permitted, provided the original author(s) and the copyright owner(s) are credited and that the original publication in this journal is cited, in accordance with accepted academic practice. No use, distribution or reproduction is permitted which does not comply with these terms. 